\title{
Design and Implementation of University Student Organization Office Automation System
}

\author{
Chenxi Li, Ru Yan* and Zhengde Bao \\ Jincheng College of Sichuan University, No.1 Xiyuan Road, High-tech West District, Chengdu, Sichuan Province, China \\ *Corresponding author
}

\begin{abstract}
Since the first office automation planning conference was held in 1985 . OA has made new changes and developments in the depth and breadth of application contents and IT technology applications and become the indispensable core application system of an organization. This article will use OA system to realize the standardization of colleges and universities student organization office work.
\end{abstract}

Keywords-university student organization; office automation system; PHP

\section{INTRODUCTION}

Student organization as a bridge between teachers and students, need a set of automation office system that keeps pace with the times to improve the efficiency of the organization and response to the incident, while reducing office hours to save office costs. Combining with the characteristics and application needs of student organizational, this article uses PHP+MYSQL+APACHE to develop OA system of student organization. To implement the standardization of Office Automation system. Completed the design of the main modules of person office system, public affairs system and resource base.

\section{The ANALYSIS AND DESIGN OF OFFICE AUTOMATION SYSTEM}

\section{A. System Requirement Analysis}

With the increase of the number of students, the development of student work and the division of student functions have been increasingly detailed, and amount of information, such as various types of data and files, is increasing day by day. Existing office processing methods such as QQ, WeChat and telephone can no longer meet the work needs of the general branch of institute. [1] Compared with the office automation system, the existing office processing methods have the following disadvantages:

1) Poor sharing

2) Mixed information

3) Insufficient office specialization

4) Delivery not timely

5) Slow speed

In this case, each student organization urgently needs to integrate the existing network and computer technology resources, develop their own OA system, utilize the mature technology of OA system, promote the circulation of data information and improve the efficiency,[2] and ultimately form a set of mature work flow.

\section{B. System Goals}

This system is designed to meet the requirements of automation office management in student organizations. Mainly achieve the following goals:

-1. Reflect the strong management capabilities of file information.

-2. Realize the management function of the basic information (personnel message) of the member, etc.

-3. Realize the information automation management function of personal office.

-4. Issue and manage meeting information.

•5. Manage the system users.

-6. Enhance data confidentiality and set the level of permissions for each user group.

•7. The system is stable and reliable.

\section{System Function Structure}

According to the system analysis, the front and background function structure of the system and the front and background login page are shown in the figure.

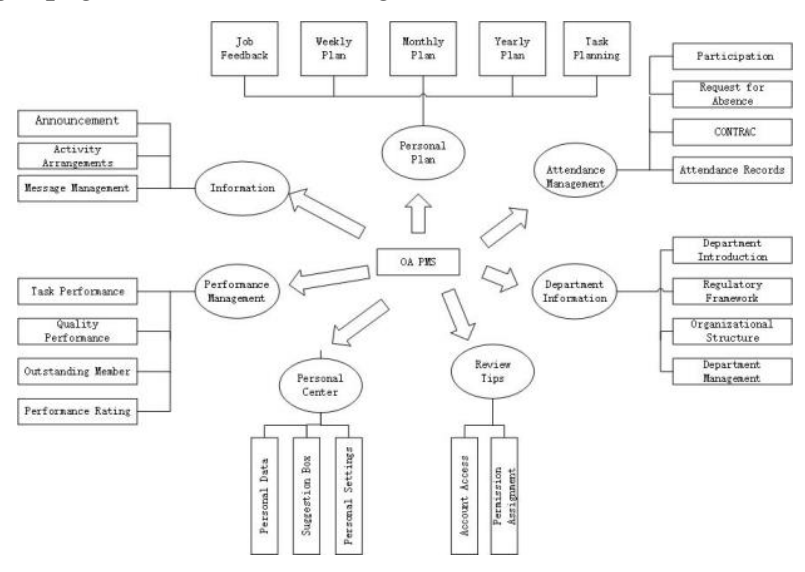

FIGURE I.
FRONT STRUCTURE CHART 


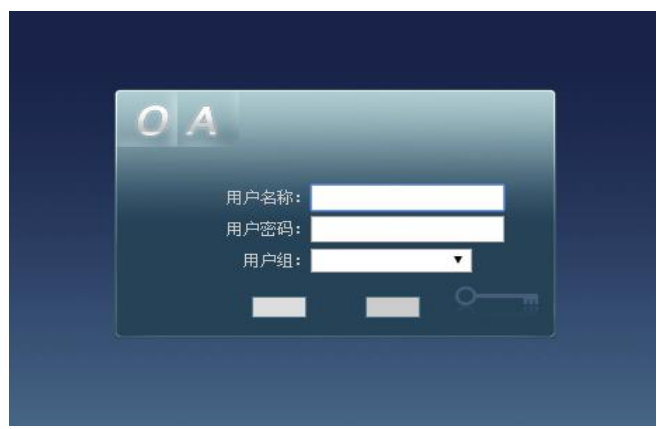

FIGURE II. Front login interface

The office automation background function structure is shown in the figure.

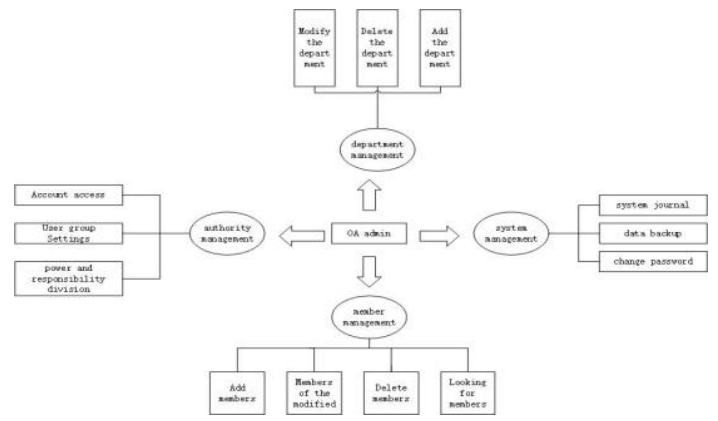

FIGURE III

BACKGROUND STRUCTURE

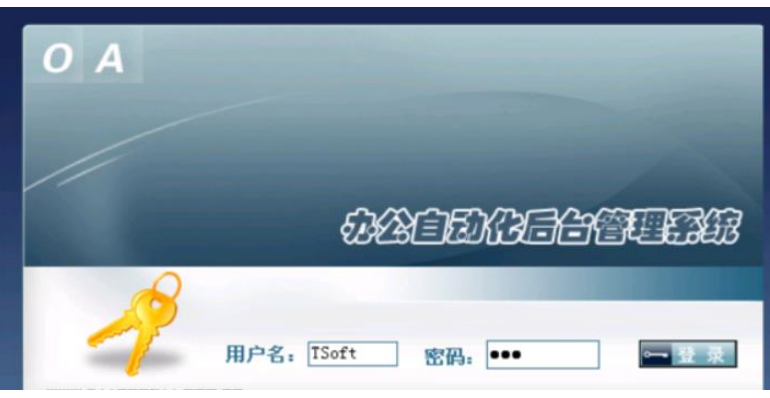

FIGURE IV. BACKGROUND LOGIN INTERFACE

\section{Database}

Since this system uses php, the database naturally uses mysql. It is not only because of the low development cost, but more importantly, the degree of tacit understanding and stability between the two are much higher than other database combinations. For a student organization, the internal office automation system is completely adequate.[3]

\section{E. Data Concept Analysis}

According to the above requirements analysis and system analysis, the main entity relation E-R diagram of the office automation management system is planned out.

\section{1) User information entity}

The user information entity includes the member's account, password, gender, and other personal data, as shown in the figure:

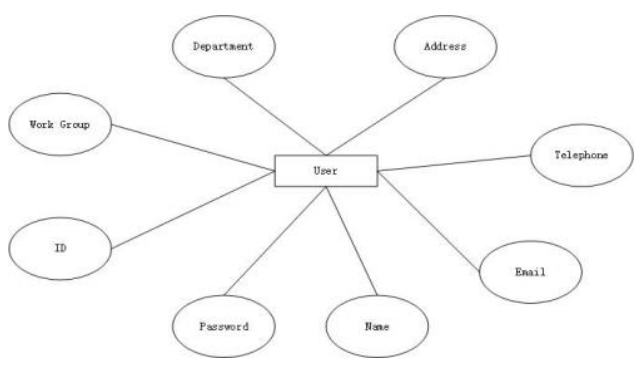

FIGURE V. USER INFORMATION ENTITY

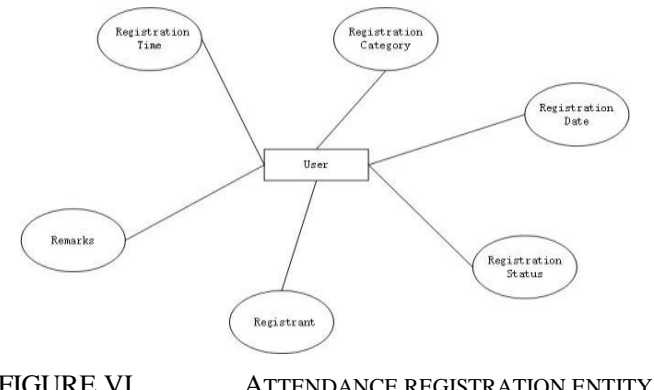

2) The attendance registration entity

The attendance registration entity includes the registration date, the registration time, the type of registration (in attendance or absence), the status of registration (late or early) and registration information, as shown in the figure:[4]

\section{F. Database Physical Structure Design}

A database db office is created in this system. A total of 13 data tables, as shown in the figure:

\begin{tabular}{c|c|c|c|} 
table & Types of & sort out & Instructions \\
\hline tb company & MySAM & Gb2312 chinese_ci & Organization information list \\
\hline tb_controller & MySAM & Gb2312 chinese_ci & Administrator list \\
\hline tb_depart & MySAM & Gb2312 chinese_ci & Department Management List \\
\hline tb_group & MySAM & Gb2312 chinese_ci & User group management list \\
\hline tb_iss & MySAM & Gb2312 chinese_ci & Audit List \\
\hline tb_list & MySAM & Gb2312 chinese_ci & function list \\
\hline tb_lyb & MySAM & Gb2312 chinese_ci & Suggestion box list \\
\hline tb_person & MySAM & Gb2312 chinese_ci & Personnel List \\
\hline tb plan & MySAM & Gb2312 chinese_ci & Plan list \\
\hline tb_register & MySAM & Gb2312 chinese_ci & Registration list \\
\hline tb_setup & MySAM & Gb2312 chinese_ci & Time list \\
\hline tb_superson & MySAM & Gb2312 chinese_ci & Excellent member list \\
\hline tb users & MySAM & Gb2312 chinese_ci & user list \\
\multicolumn{4}{|c|}{ FIGURE VII. }
\end{tabular}

\begin{tabular}{|c|c|c|c|c|c|c|}
\hline Fields & Types of & sort out & NULL & default & additional & Instructions \\
\hline Id & $\operatorname{lnt}(4)$ & & NO & & auto_increment & auto numbering \\
\hline U_ user & Varchar(50) & Gb2312_chinese.ci & NO & & & user account \\
\hline u_pwd & Varchar(20) & Gb2312_chinese_ci & NO & & & user password \\
\hline U_name & Varchar(20) & Gb2312_chinese._i & YES & NULL & & user name \\
\hline U_sex & char(1) & Gb2312_chinese.ci & YES & & & User gender \\
\hline U_ birth & date & Gb2312_chinese_ci & YES & & & User's birthday \\
\hline U_address & Varchar(50) & Gb2312_chinese_ci & YES & & & User address \\
\hline U_tel & Varchar(20) & Gb2312_chinese_ci & YES & & & User phone \\
\hline U_email & Varchar(50) & Gb2312_chinese.ci & YES & & & User email \\
\hline U_depart & Varchar(20) & Gb2312_chinese_ci & NO & & & Department \\
\hline U_on & $\operatorname{lnt}(1)$ & Gb2312_chinese_ci & NO & & & Activate the account \\
\hline
\end{tabular}

The user list is mainly used to store employee's name, gender, and other public information related to departments and working groups. The data structure is shown in the figure: 
The personnel lists are used to store information published by the personnel department, such as title, content, time, etc. As shown in the figure:[5]

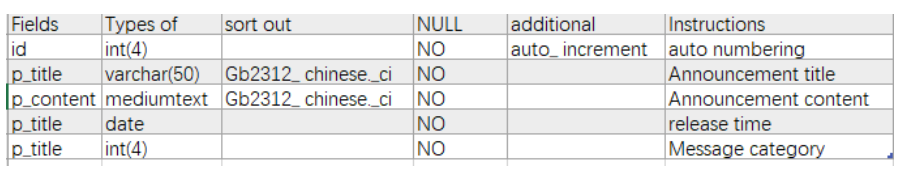

FIGURE IX. PERSONNEL LIST

III. The Implementation of System Function

\section{A. The Implementation of Front-end Module Interface}

According to the frequency and importance of each functional module, the main modules in the front page of this system are mainly 3 parts:

Home navigation: Includes current user, department, current time, home page, re-login and logout.

Left navigation: Includes each management module and sort.

1. Information module: Including company profile, rules and regulations, organizational structure and business management.

2. Performance module: Including task performance, quality performance and performance evaluation.

3. Personnel information module: Including enterprise announcements, event scheduling and message management.

4. Audit instruction module: Including release and instruct audits.

5. Attendance management module: Including commute registration, sick leave registration, overtime registration and attendance settings.

6. Personal planning module: Including job feedback, weekly plan, monthly plan, annual plan and task plan.

7. Member universe module: Including member views, comment boxes and personal settings.

Main display area: Default display bulletin, event scheduling, and personal plans and approvals.

The Two-column structure layout adopted at the Front Page of the office automation management system. The characteristics of the two-column layout are concise, decent, and distinctive personality. Its frame design is flexible and varied according to the changes in its content form. It is very consistent with the style of office automation management system. The specific application of frame layout in this system is as follows:

$<$ frameset rows="111,*" cols="*" frameborder="no" border="0" framespacing="0">

<frame src="top.php" name="topFrame" scrolling="No" noresize="noresize" id="topFrame" title="topFrame" />

$<$ frameset rows="*" cols="220,*" framespacing="0" frameborder="not" border="0"> <frame src="left.php" name="leftFrame" scrolling="auto" noresize="noresize" id="leftFrame" title="leftFrame" />

<frame src="main.php" name="mainFrame" scrolling="auto" id="mainFrame" title="mainFrame" />

$</$ frameset $>$

$</$ frameset $>$

$<$ noframes $><$ body $>$

$</$ body $>$

$</$ noframes $>$

\section{B. The Implementation of Personnel Message Module}

The personnel message module mainly contains two part, one is for all users, including viewing announcements, activities, opinion boxes, etc. The other is only open to personnel management departments, other users do not allow, will not see the page, such as announcement management, opinion management, etc. In the personnel message module, the announcement and the activity arrangement are displayed on the same display page. To distinguish the different operations, a $\mathrm{u}$-id value needs to be passed to the display page, and different types of content are obtained according to the different $\mathrm{u}$-id values in the data table. The way to pass value is url and form.[6]

1) The implementation process of message management

-Click on "Message Management" in the "Personnel Messages" drop-down list. A message management page is displayed in the main frame, showing a list of post messages and operations on messages, including "modify," "delete," and "post new messages." On this page, the system first checks whether the user is logged in and whether the link is illegal through the permission checking file. If the system is judged illegal, the system will shut down directly; if there is no exception, the system will continue to execute the following code. When the user passes the check, the system will access the database and read the message from the personnel message data table (tb_person). Publication time, message title displayed on the page, and set "modify" and "delete" for each piece of data through id. The program key code is as follows:
$<$ ?php
session_start();
include "../inc/chec.php";
include "../conn/conn.php";
?>
$<$ link href="../css/style.css" rel="stylesheet" />
$<$ script $\mathrm{src}=" . . / \mathrm{js} / \mathrm{client}$ js.js" $></$ script $>$
$<$ ?php 
\$sqlstr = "select id,p_time,p_title from tb_person";

\$result = mysql_query $($ \$sqlstr, $\$$ conn $)$;

while $($ Srows $=$ mysql_fetch_row $($ Sresult $))\{$

echo "<tr >";

for $(\$ i=1 ; \$ i<\operatorname{count}(\$ r o w s) ; \$ i++)\{$

echo $\quad "<\mathrm{td} \quad$ height=30 style='text-indent: 30px;'>".\$rows[\$i]."</td >";

$$
\text { \} }
$$

echo

$"<\mathrm{td}><\mathrm{a}$

href='m_message.php?id=".\$rows[0]."'>CHANGE $</ \mathrm{a}>/<\mathrm{a}$

href='d_message_chk.php?id=".\$rows[0]."' onclick='return del_mess();'>DELETE $</ \mathrm{a}></ \mathrm{td}>$ ";

$$
\text { echo "</tr }>\text { "; }
$$

|******************************/

?>

$<\operatorname{tr}>$

$<$ td height="30" align="right" valign="middle" colspan="3" $><\mathrm{a}$ href='add_manage.php' target $=$ "mainFrame" $>\mathrm{NEW}</ \mathrm{a}></ \mathrm{td}>$

$</ \operatorname{tr}>$

\section{Attendance Module Design}

The attendance function is one of the functional modules used in the office automation management system every day, which is also one of the important modules. In addition to the normal registration function, the special registration functions including registration of sick leave and overtime registration are also included. The administrator can set the standard time for work and overtime for attendance records.

1) The main functions of the attendance module are:

-Daily registration: Includes work and off-duty registration.

-Sick leave registration: Includes sick leave and personal leave registration.

-Overtime registration: Includes the registration of overtime work and overtime work.

-Attendance record: Includes standard time setting and overtime standard.

2) The program key code is as follows: $<$ ?php

\$conn = mysq1_connect("localhost","root","root");

mysql_select_db("db_office",\$conn);

mysql_query("set names gb2312");

\$sqlstr = "select $*$ from tb_setup";

\$result = mysql_query $(\$ s q 1 s t r, \$ c o n n)$; \$rows_1 = mysql_fetch_row(\$result);

\$str = "mysql_fetch_rows: ".\$rows_1[0]."<br>";

\$rows_2 = mysql_fetch_array(\$result);

\$str .="mysql_fetch_array: ".\$rows_2[id]."<br>";

\$rows_3 = mysql_fetch_object(\$result);

\$str .= "mysql_fetch_object: ".\$rows_3->id."<br>";

echo "<script>alert('".\$str."');</script>";

?>

3) The implementation procedure of commute registration

In the actual needs of the student organization, there are staff on duty in each department office who also need field personnel to hold the activities, and the office on-duty personnel use the same system. There is no actual display distinction between commuting and leaving the field.

On the commutation registration page, the user's registration record set is returned from the data table tb_register and displayed on the page by login user id. When displaying data, it is necessary to make two judgments: one to judge the user's registration type (on or off duty), one to judge the user's registration status (late, early retreat, punctual commuting). In the registration interface, there are three form elements and one hidden form, as shown in Table:

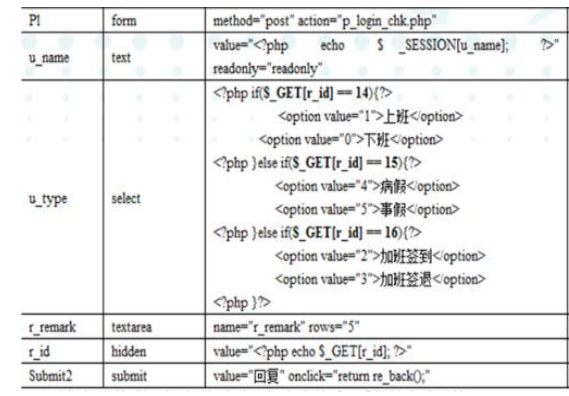

FIGURE X

FORM ELEMENT FOR REGISTRATION

Select the corresponding registration type, such as work, and submit the form, and the system will skip to the processing page (p_login_chk.php). In the processing page, the first judgment is the type of registration (work, off duty), and then according to the type of registration corresponding to the standard time, through the comparison of two time, get registration status (late, early retreat, punctual commuting), and finally perform the insert statements, add new records.

\section{The Design of Back-end Management}

The main functions of the background home page of the office automation management system are as follows:

Home navigation: Includes current time, home page, re-login and logon.

Left navigation: Includes various management modules and classifications. 
Department admin module: Mainly used for the operation of department information, including add, modify, delete and view functions.

Personnel admin module: Mainly used for the unified management of member information, including add, modify, delete and find staff.

Authority management module: Mainly used to assign functional rights to departments, members and user groups.

System management module: To maintain system log, modify administrator password and backup system data.

The layout of the background page and the front page is similar, with the frame structure of "fixed above and left nested". The banner and head navigation are displayed in the top frame and the function list is displayed in the left frame. The middle display area (manFrame) displays the forms at all levels.

\section{E. The Implementation of Department Management Module}

\section{1) Department management overview}

Background management main interface:

The department management module consists of two parts:

a) Viewing department:

Look at each department name and the relationship between departments, can also change the department information and level, if it is the lowest department, it can be deleted.

\section{b) Add department:}

You can add new department, including department name, superior department and department remarks.

\section{SUMMARY}

The OA system based on php helps college students to realize share information resources, enhance the ability of cooperative work among members, strengthen supervision and management of leaders, effectively manage tangible (equipment, etc.), intangible (business information, knowledge) assets, and avoid loss. Realize the administrative affairs such as document circulation, auditing, signing and approving, promote electronic and standardized management, and perfectly integrate the information flow within the organization.

\section{REFERENCES}

[1] PHP from Getting Started to Proficient (4th Edition). Tsinghua University Press June 2017 4th Edition.

[2] Cheng Jiahua. Design and Implementation of Office Automation System Based on $\mathrm{B} / \mathrm{S}$ Mode[J]. Intelligent Computers \& Applications, 2005(1):6-7.

[3] Wang Yanyan. Design and Implementation of Enterprise Office Automation System Based on Workflow [D]. University of Electronic Science and Technology, 2015.

[4] Peng Liuyong. Design and Implementation of Document Delivery System Based on B/S Architecture[D]. Zhengzhou University, 2013.

[5] Fu Sizhou. Design and Implementation of Office Automation Management System [D]. Nanchang University, 2015.

[6] Sun Jianliang. Discussion on PHP Database Access Technology: Taking MySQL Database Access as an Example[J]. Journal of Farm Science and Technology, 2014,(6). 